\title{
MOTION OF PIGMENTS IN THIN PAINT FILMS
}

\author{
Marina Curak, Dr. Nazli Saranjam, Dr. Sanjeev Chandra \\ Department of Mechanical and Industrial Engineering \\ University of Toronto \\ Toronto, Canada \\ mcurak@mie.utoronto.ca, nazlis@mie.utoronto.ca, \\ chandra@mie.utoronto.ca
}

\begin{abstract}
When thin paint layers are exposed to heat, evaporation of the solvent begins, and significant movement within the paint film occur, causing temperature and concentration gradients. A clear coat paint was used, which had a density of $988 \mathrm{~kg} / \mathrm{m}^{3}$, viscosity of $240 \mathrm{cP}$ and a surface tension of $26 \mathrm{mN} / \mathrm{m}$ and was mixed with spherical solid blue particles with a mean diameter $26 \mu \mathrm{m}$ were added to the paint at $2 \%$ concentration of the total mass. A knife edge was used to coat stainless steel substrates at different thicknesses and placed in a convection oven at $121^{\circ} \mathrm{C}$ for 30 minutes. Images of the samples during the curing process were taken, showing how the pigments moved from low to high surface tension areas. Colour measurements were taken to show that increasing the thickness of the same paint significantly decreases the lightness value.
\end{abstract}

Keywords-component; Mass transfer and drying, colour, boiling and evaporation, two-phase flow, surface-tension-driven, concentration gradient, self-organizing patterns, automotive paint

\section{INTRODUCTION}

The paint applied on a car serves two functions: to appear attractive and uniform in colour, as well as protecting the car from abrasion and corrosion. In recent years, the automotive industry has been investigating the incorporation of metallic pigments within solvent based paints, due to their visual appeal and increased ability to protect against the aforementioned factors [1]. However, the manufacturing process of spraying this paint onto car parts does not yield consistent colour reading results [1]. This problem was approached in two directions; varying the composition of the paint, and varying the coating process of the paint.

The location of the pigments within the paint film significantly impacts the colour of a sample [2]. Kirchner and Houweling [2] conducted a study on changing the paint composition to use different types of metallic pigments of different shape and surface roughness with various toners and metallic pigment orientation controlling agents. Their results for solvent based paints stated that flop controlling agents had limited success on improving the orientation of the metallic pigments, with just $1^{\circ}$ decrease in the flop angle [2]. The conclusions were that other alternative mechanisms are responsible for the disorientation of pigments, but it was still unclear as to what those mechanisms were [2]. Kirchner [3] then conducted another study, which was focused on the orientation of the pigments during the curing process from a cross sectional perspective. It was determined that the evaporation of the solvent does significantly influence the orientation of the pigments, however is again is not the only mechanism causing it [3].

This, film shrinkage, that Kirchner [3] investigated is caused by a well-researched effect. Once a sample is exposed to heat in a convection oven, convective cells (Bénard-Marangoni cells) begin forming as a result from concentration and temperature gradients $[4,5]$. These convective cells move from low to high surface tension areas [4]. In paint applications, once the BénardMarangoni cells occur and all the solvents has evaporated, the paint beings to harden in these hexagonal structures, creating an effect known as "orange peel", which is defined by a surface resembling the skin of an orange [6]. It is not desirable to this effect occur, as the increased roughness due to the waves from the hardened Bénard-Marangoni cells adversely impacts the colour readings of the paint samples [7].

This paper will focus on changing the thickness of the paint with solid spherical nonmetallic pigments, as these pigments used in this study are within the same order of magnitude of the metallic pigments used in the automotive industry.

\section{EXPERIMENTAL SYSTEM}

A clear coat model paint was used, which had a density of 988 $\mathrm{kg} / \mathrm{m}^{3}$, viscosity of $240 \mathrm{cP}$ and a surface tension of $26 \mathrm{mN} / \mathrm{m}$ [6]. Spherical solid blue particles of a mean diameter $26 \mu \mathrm{m}$ were added to the paint, at a concentration of $2 \%$ of the total mass of the paint. A knife edge, shown in Figure 1, was used to coat reflective stainless steel substrates with a diameter of $50.8 \mathrm{~mm}$ and a surface roughness of $0.1 \mu \mathrm{m}$.

Funding for this project was provided by NSERC and Magna Exteriors. 


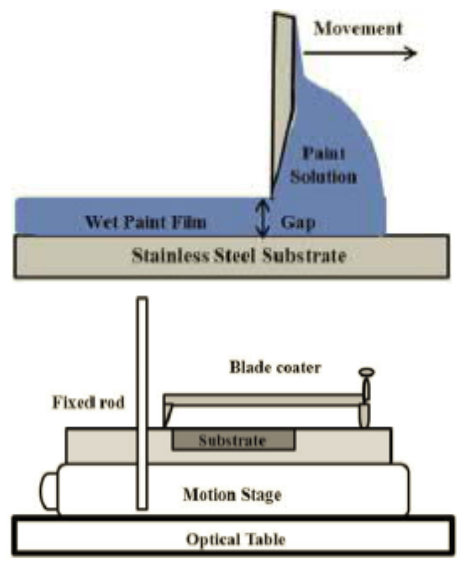

Figure 1. Knife edge coating apparatus [6]

After each sample was coated, it was given a flash off time of 20 seconds before it was placed in the oven, to avoid air entrapment within the sample. The sample was then placed in the convection oven to bake for 30 minutes at approximately $121.1^{\circ} \mathrm{C}^{+} / 1.5^{\circ} \mathrm{C}$

Figure 2 shows the schematic of the experimental system of the convection oven. Two flexible heating sheets at $1.55 \mathrm{~W} / \mathrm{cm}^{2}$ were placed on opposing sides of the oven and secured with an adhesive. Each heating sheet was connected to a variac, which was then connected to a temperature controller. This controller received readings from the thermocouple placed behind each heating sheet. An additional thermocouple was placed right beside the sample in the oven, to continuously measure the temperature. Excluding the oven's legs and the observation window, the rest of the oven was covered with thermal insulation to reduce the heat loss. The sample was then observed with a Pixelink PL-D7715CU-T camera with a resolution of $4608 \times 3288$ [8], which took images during the curing process. Mass measurements were collected every 60 seconds with a resolution of $0.1 \mathrm{mg}$.
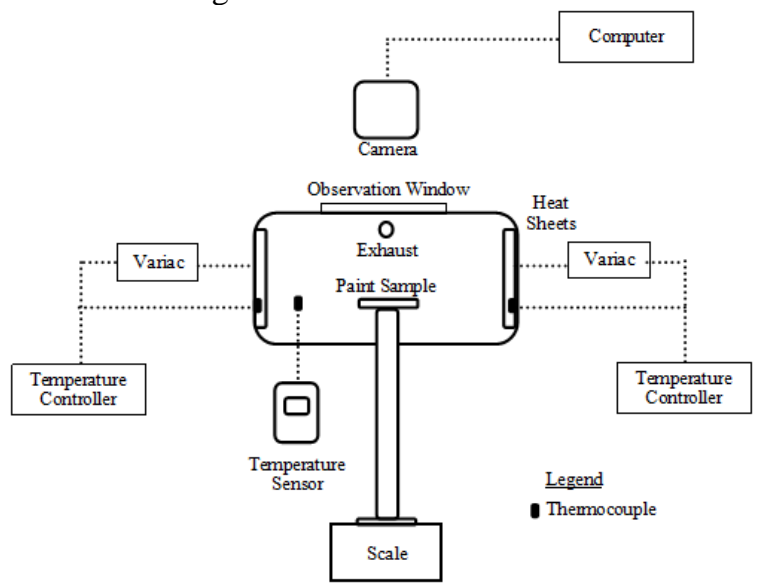

Figure 2. Convection oven curing system

\section{RESULTS AND DISCUSSION}

Once the sample is placed in the oven, the solvent begins to evaporate, causing the paint resin and pigments to move. This creates concentration and density gradients within the paint film, which results in surface tension gradients.

Figures 3 to 5 (with Figures 4 and 5 on the following page) show how the pigments move within the Bénard-Marangoni cells throughout this curing time. The initial thicknesses were extrapolated by determining the volume of the paint on the substrate and measuring the mass of the substrate. The field of view in each photo is $5.7 \mathrm{~mm}$ wide.

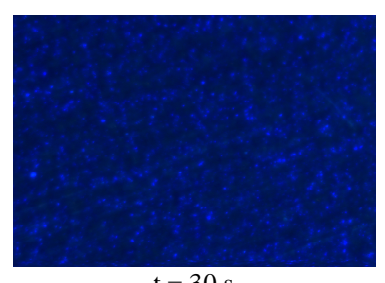

$\mathrm{t}=30 \mathrm{~s}$

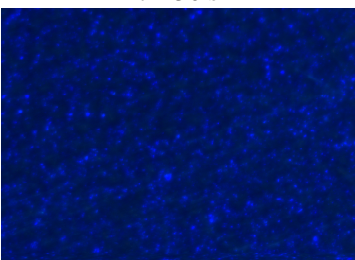

$\mathrm{t}=1 \min$

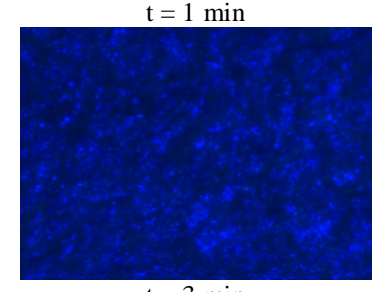

$\mathrm{t}=3 \mathrm{~min}$

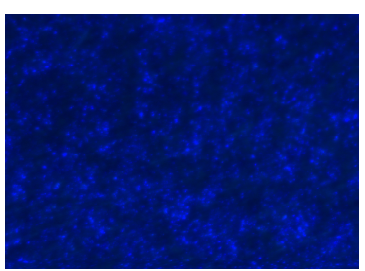

$\mathrm{t}=4 \mathrm{~min}$

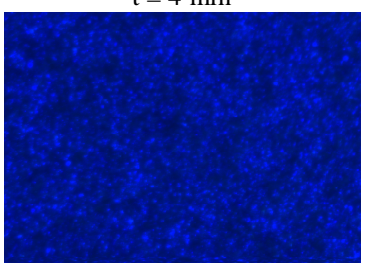

$\mathrm{t}=10 \min$

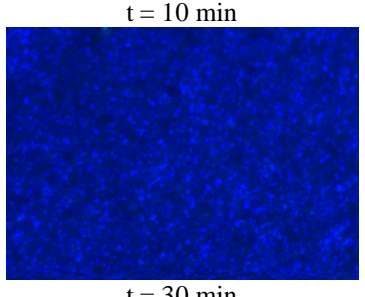

$\mathrm{t}=30 \mathrm{~min}$
Figure 3. $300 \mu \mathrm{m}$ sample blue pigments moving within the Bénard-Marangoni cells

In Figure 3, at $\mathrm{t}=30$ seconds, the boundaries of the BénardMarangoni cells at the $300 \mu \mathrm{m}$ sample are present. After $\mathrm{t}=3$ minutes, the $300 \mu \mathrm{m}$ sample appears to have a significant decrease in magnitude, as the changes between the images in minutes 3 to 4 are negligible. At $540 \mu \mathrm{m}$, Figure 4 shows that there is continuous movement of the pigments for the first 4 minutes before the velocity magnitude decreases, with significantly larger Bénard-Marangoni cells than shown in Figure 3. Lastly, Figure 5 shows the pigments moving within the Bénard-Marangoni cells within the first 6 minutes of the curing process. Similarly seen in Saranjam [6], a secondary quasi-stationary period, with elongated cells are observed after the primary Bénard-Marangoni cells. 


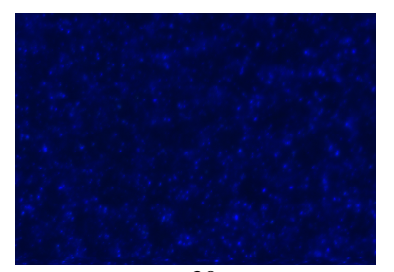

$\mathrm{t}=30 \mathrm{~s}$

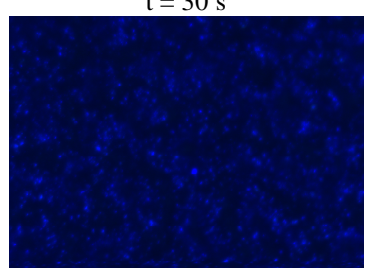

$\mathrm{t}=1 \mathrm{~min}$

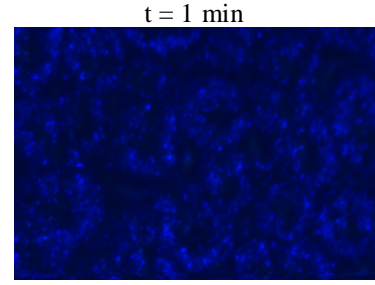

$\mathrm{t}=2 \min$

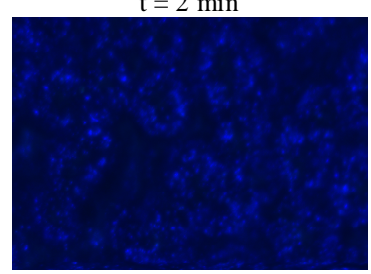

$\mathrm{t}=2.5 \mathrm{~min}$

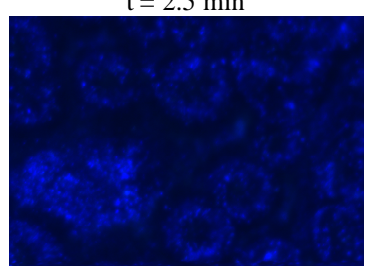

$\mathrm{t}=3 \min$

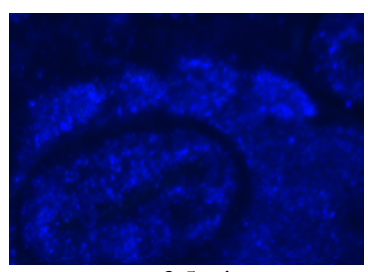

$\mathrm{t}=3.5 \mathrm{~min}$

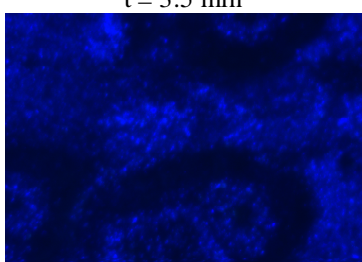

$\mathrm{t}=4 \min$

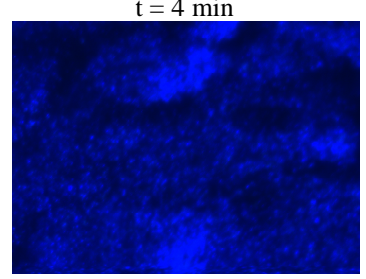

$\mathrm{t}=5 \mathrm{~min}$

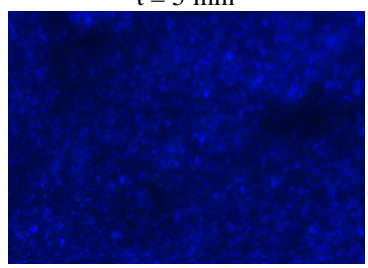

$\mathrm{t}=10 \mathrm{~min}$

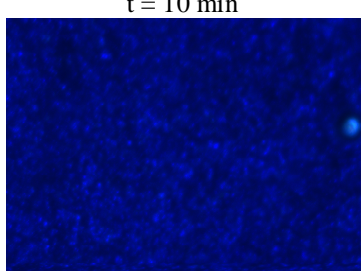

$\mathrm{t}=30 \mathrm{~min}$

Figure 4. $540 \mu \mathrm{m}$ sample blue pigments moving within the Bénard-Marangoni cells

All the images collected during the curing process were then analyzed using Particle Image Velocimetry (PIV) in Matlab [9, 10, 11], which calculated the velocity magnitude between frames throughout the 30 -minute curing process, which is shown in Figure 6.

This PIV analysis concludes what Figures 3-5 already show- the larger the paint film thickness, longer the pigments move within their cells. Additionally, Figure 6 shows that the velocity of these pigments increases with increasing paint thicknesses. This is expected as there is more solvent and pigments that would cause greater concentration gradients and therefore higher surface tension gradient.

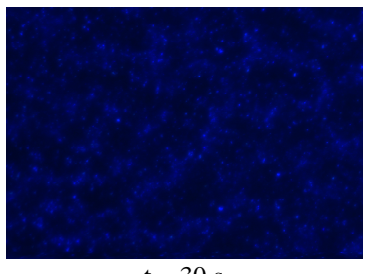

$\mathrm{t}=30 \mathrm{~s}$

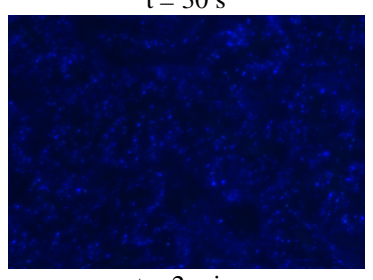

$\mathrm{t}=2 \min$

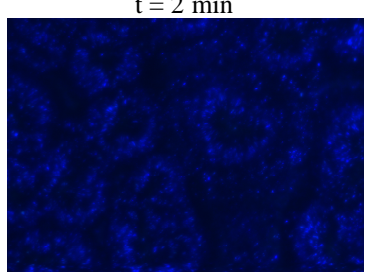

$\mathrm{t}=2.5 \mathrm{~min}$

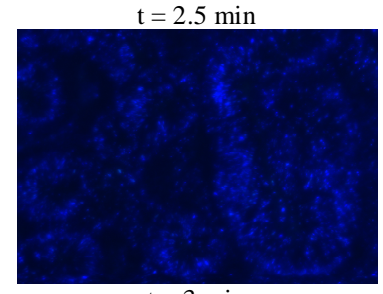

$\mathrm{t}=3 \min$

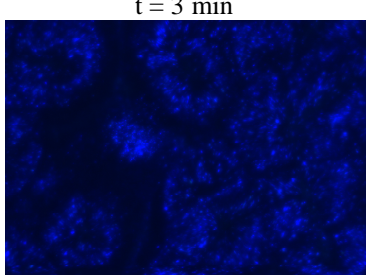

$\mathrm{t}=3.5 \mathrm{~min}$

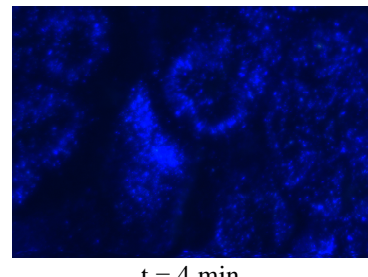

$\mathrm{t}=4 \mathrm{~min}$

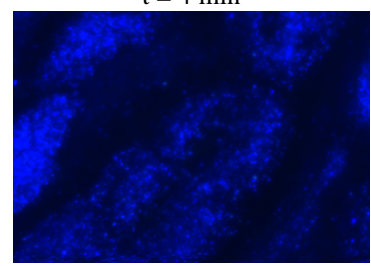

$\mathrm{t}=5 \mathrm{~min}$

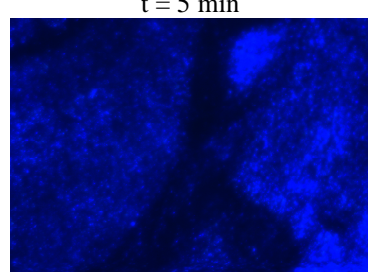

$\mathrm{t}=6 \mathrm{~min}$

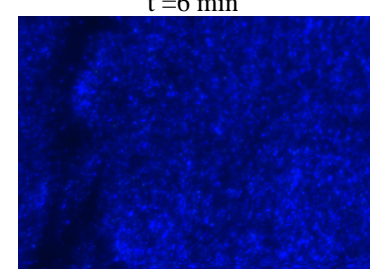

$\mathrm{t}=10 \mathrm{~min}$

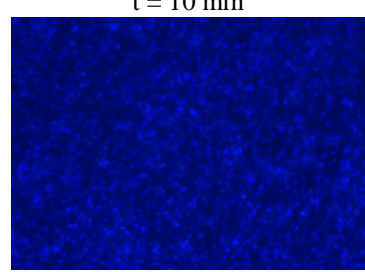

$\mathrm{t}=30 \mathrm{~min}$

Figure 5. $750 \mu \mathrm{m}$ sample blue pigments moving within the Bénard-Marangoni cells

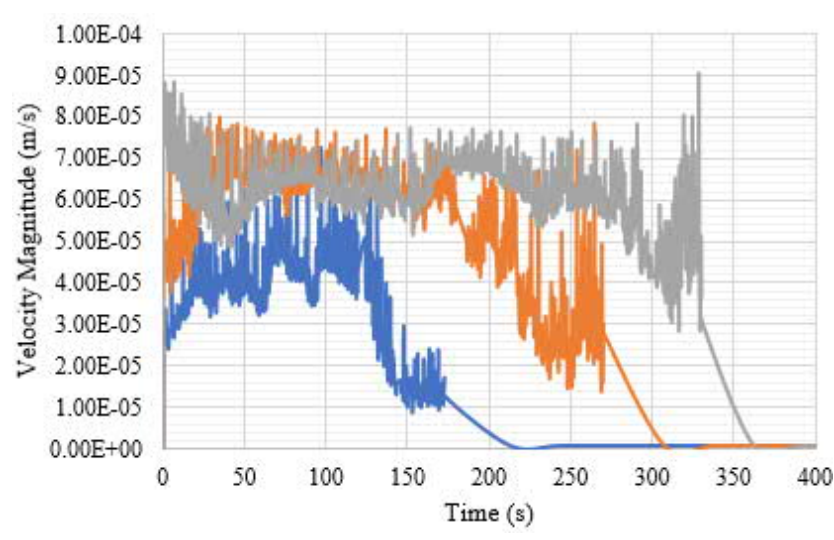

Figure 6. Velocity magnitude of the pigments within the paint. $300 \mu \mathrm{m}$ in blue, $540 \mu \mathrm{m}$ in orange and $750 \mu \mathrm{m}$ in grey. 
After the samples were cooled, their colour was measured using the Nix Color Pro Sensor [12]. This sensor can be used under different lighting and observation angle conditions. The lighting condition was set to illuminate at the $\mathrm{D} 65^{\circ}$ setting, which simulates daylight, and both observation angles of $2^{\circ}$ and $10^{\circ}$ were used [12]. This is to simulate the multiple different observation angles that is used in the automotive industry [13]. The sensor measured colour using the CIELAB colour space, as it is the standard used in industry [13], and the colour was measured in 5 different places on the sample. In the CIELAB colour space, parameters are linearly proportional to the change in colour. Figure 7 shows how many units the parameters, lightness (L), the red to green value (a), and yellow to blue value (b) change from the initial colour of the substrate, where an increase in any parameter corresponds to the name of the parameter, and a decrease corresponds to the converse of the parameter's name [13]. Since the human eye is most susceptible to changes in the lightness value, it is that change in parameter that has the most significance in colour standards [14]. Figure 7 shows the change in CIELAB colour readings from the sample's colour reading minus the reflective substrate's colour reading. Since the difference in colour readings between the observation angles are negligible, the readings taken at an observation angle of $10^{\circ}$ is shown in Figure 7.

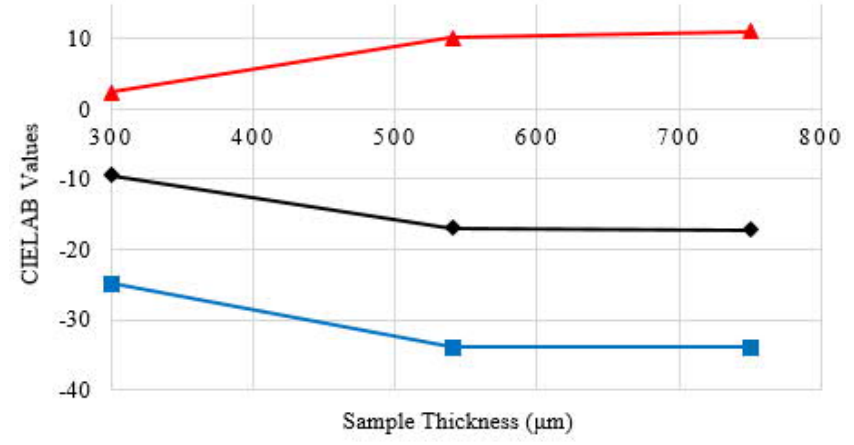

Figure 7. Change in colour readings reading at observation angle $10^{\circ} \mathrm{L}$ is grey, a is green, and b is yellow.

The most significant change colour change occurred by increasing the paint's thickness from 300 to $540 \mu \mathrm{m}$. This increase made the $540 \mu \mathrm{m}$ appear to be darker, redder and bluer. Meanwhile, the increase in paint thickness from 540 to $750 \mu \mathrm{m}$ did not have as large of an impact, with the $750 \mu \mathrm{m}$ sample appearing darker and redder.

\section{CONCLUSION AND FUTURE WORK}

During the paint curing process, evaporation of the solvent creates concentration and temperature gradient throughout the paint film. The thickness of the paint moves the pigments within the paint, outlining the Bénard-Marangoni cells which occurs due to the fluid moving from low to high surface tension areas. The velocity magnitude of the pigments moving between these low to high surface tension areas increases as the paint thickness increases. The understanding of this flow will be essential for the next sets of tests involving metallic pigments-with a significantly larger size and shape at different amounts.

The thicker paint films resulted in significantly darker colour readings. These set of tests will be repeated with a lowered percentage of pigments to total paint mass; to observe this effect on the velocity magnitude and colour.

With these variation of the paint composition, an analytical mass diffusion analysis will be compared to the experimental results and the concentration gradients will be calculated, to see the paint composition's effect on the mass diffusion.

\section{REFERENCES}

[1] H. Streitberger and K. Dossel, Automotive paints and coatings, 2nd ed. Weinheim: Wiley-VCH, 2008

[2] E. Kirchner and J. Houweling, "Measuring flake orientation for metallic coatings", Progress in Organic Coatings, vol. 64, no. 2-3, pp. 287-293, 2009.

[3] E. Kirchner, "Film shrinkage and flake orientation", Progress in Organic Coatings, vol. 65, no. 3, pp. 333-336, 2009.

[4] H. Bénard, "Les tourbillons cellulaires dans une nappe liquide. - Méthodes optiques d'observation et d'enregistrement", Journal de Physique Théorique et Appliquée, vol. 10, no. 1, pp. 254-266, 1901.

[5] C. Hansen and P. Pierce, "Cellular Convection in Polymer Coatings-An Assessment", Industrial \& Engineering Chemistry Product Research and Development, vol. 12, no. 1, pp. 67-70, 1973.

[6] N. Saranjam, "Transport Phenomena in Drying Paint Films", Ph.D, University of Toronto, 2016.

[7] Introduction-Orange Peel. Geretsried: BYK-Gardner GmbH, 2018, pp. 33-36. [Online]. Available:

http://www.byk.com/fileadmin/byk/support/instruments/theory/appearan ce/en/Intro_Orange-Peel.pdf. [Accessed: 25- Aug- 2016].

[8] "PL-D7715CU-T Aptina MT9F002 Machine Vision Camera", Pixelink Industrial Cameras, A Navitar Company. [Online]. Available: http://pixelink.com/product/pl-d7715cu-t-aptina-mt9f002/. [Accessed: 14- Feb- 2017].

[9] ] Thielicke, W. \& Stamhuis, E.J. (2014). PIVlab - Towards User-friendly, Affordable and Accurate Digital Particle Image Velocimetry in MATLAB. Journal of Open Research Software 2(1):e30, DOI: http://dx.doi.org/10.5334/jors.bl.

[10] Thielicke, W. \& Stamhuis, E.J. (2014): PIVlab - Time-Resolved Digital Particle Image Velocimetry Tool for MATLAB (version: 1.41), DOI: http://dx.doi.org/10.6084/m9.figshare.1092508.

[11] Thielicke, W. (2014): The Flapping Flight of Birds - Analysis and Application. Phd thesis, Rijksuniversiteit Groningen, http://irs.ub.rug.nl/ppn/382783069

[12] Nix Pro Tech Specs. Hamilton: Nix Sensor Ltd. [Online]. Available: http://www.ghinstruments.com/wp-content/uploads/2017/08/Nix-ProTech-Specs-Digital_8-10-17.pdf. [Accessed: 10- Jan- 2017].

[13] BYK-mac i COLOR. Gerestried: BYK, pp. 111-121. [Online]. Available: http://www.kohsieh.com.tw/PDF_Files/BYKGardner/03_Color/02_Metallic_Color/BYK-mac_i_COLOR.pdf. [Accessed: 25- Aug- 2016].

[14] A. 14(2017), "ASTM E2539 - 14(2017) Standard Test Method for Multiangle Color Measurement of Interference Pigments", Astm.org, 2018. [Online]. Available: https://www.astm.org/Standards/E2539.htm. [Accessed: 14- Feb- 2018]. 